\title{
Pharmacokinetics of Granisetron in Adults and Children with Malignant Diseases
}

\author{
Ikuo Wada, ${ }^{*, a}$ Takeo Takeda, ${ }^{b}$ Michiko Sato, ${ }^{c}$ Hiroshi Saitoh, ${ }^{c}$ Takehito Nakabayashi, ${ }^{b}$ \\ Kouzo Mino, ${ }^{b}$ Takanori Honma, ${ }^{b}$ Masahiko TaKadA, ${ }^{c}$ and Kazuyuki Hirano ${ }^{d}$ \\ Hokkaido University Dental Hospital, ${ }^{a}$ Kita 13-jo, Nishi 6-chome, Kita-ku, Sapporo 060-8586, Japan, Sapporo National \\ Hospital, ${ }^{b}$ 4-jo, 2-chome, Kikusui, Shiroishi-ku, Sapporo 003-0804, Japan, Health Science University of Hokkaido, ${ }^{c} 1757$ \\ Kanazawa, Ishikari-Tobetsu, Hokkaido 061-0293, Japan, and Gifu Pharmaceutical University, ${ }^{d}$ 5-6-1 Mitahora-Higashi, \\ Gifu 502-8585, Japan. Received August 3, 2000; accepted January 9, 2001
}

\begin{abstract}
Granisetron (GRN) is widely used for patients with various cancers who suffer from chemotherapy-induced vomiting and nausea. The, pharmacokinetics of GRN has not been fully evaluated in such patients, however, and its dosage regimen is still controversial. In this study, we determined GRN levels in serum and urine from lung cancer patients and children suffering from cancer after intravenous infusion. In lung cancer patients, the interindividual variations in $t_{1 / 2 \beta}$, area under the concentration-time curve $(A U C)$, and $V d_{\beta}$ were relatively smaller than expected from previous reports on healthy subjects, while $t_{1 / 2 \beta}$ was prolonged more than 5-fold in healthy subjects. Urinary excretion of unchanged GRN in lung cancer patients was $c a .15 \%$ of dose, consistent with previous reports, and one individual demonstrated an even higher urinary excretion (ca. 45\%). The pharmacokinetic parameters of GRN in child cancer patients varied markedly among individuals, and some child patients had smaller $t_{1 / 2 \beta}$ than adult patients. In these cases, GRN should be administered at shorter intervals. These results suggested that a pharmacokinetic study of GRN was necessary for planning a dosage regimen and managing chemotherapy-induced vomiting and nausea.
\end{abstract}

Key words granisetron; pharmacokinetics; lung cancer patient; child; chemotherapy

Granisetron (GRN), a potent and selective 5-hydroxytryptamine $_{3}\left(5-\mathrm{HT}_{3}\right)$ receptor antagonist, is considered to be a potent anti-emetic agent in the control of chemotherapy-induced nausea and vomiting. ${ }^{1)}$ Many reports have described that GRN is effective against acute vomiting and that the agent, as well as other $5-\mathrm{HT}_{3}$ receptor antagonists, is less effective against delayed emesis. ${ }^{1)}$ Delayed vomiting is not associated with serotonin release. ${ }^{2)}$ As a matter of fact, however, GRN has often been given for delayed vomiting during chemotherapy. Therefore, an adequate dosage regimen of GRN is required for patients with various malignant diseases.

Since GRN was first developed as an injection, few data are available on the pharmacokinetic properties of its intravenous administration to healthy subjects and various cancer patients. According to a previous review, ${ }^{3)}$ the mean $\beta$-phase elimination of half-time $\left(t_{1 / 2 \beta}\right)$ of intravenous GRN was 9 to $11.6 \mathrm{~h}$ in cancer patients, more than double that in healthy subjects. Moreover, total clearance $\left(C L_{\mathrm{tot}}\right)$ in cancer patients was nearly half that in healthy subjects, resulting in a 2-fold or greater increase in area under the concentration-time curve $(A U C)$ for cancer patients. These results indicate that pharmacokinetic information from healthy subjects is not always applicable for predicting blood levels of GRN in cancer patients. It should be noted that pharmacokinetics of GRN in these patients is changeable according to the type and stage of cancer. Moreover, there seems to be considerable inter-individual variability for $A U C$ both in healthy subjects and cancer patients. ${ }^{3)}$ Since GRN is a potent substrate of CYP3A4, ${ }^{4)}$ remarkable inter-individual differences in pharmacokinetic parameters might, in part, be attributed to changes in CYP3A4 activity. ${ }^{\text {) }}$

GRN is also administered to children with cancer. However, little information is currently available on its pharmacokinetics in these patients. ${ }^{6}$ We recently developed a rapid and reliable assay method for measuring GRN in serum and urine by HPLC. ${ }^{7)}$ In this study, we determined GRN levels in serum and/or urine from seven adult patients with lung cancer and seven child patients with malignant disease following intravenous infusion, and evaluated their pharmacokinetic parameters.

\section{MATERIALS AND METHODS}

Materials GRN and BRL 43693A were kindly provided by Smith Kline Beecham Pharm. Co. (Tokyo, Japan). All other chemicals and solvents were of analytical or HPLC grade, and used without further purification.

Administration of GRN Seven adult and seven child patients hospitalized in Sapporo National Hospital participated in this study. Informed consent was obtained from all adult patients and from parents of the children after full explanation of the purpose and procedures of this study. Patient diagnoses and characteristics are listed in Tables 1 and 2. In this study, GRN was administered only once for the control of the first episode of nausea. For subsequent episodes, other anti-emetic agents like ondansetron were used. The dose of GRN was $3 \mathrm{mg}$ for adult and $1-3 \mathrm{mg}$ for children. GRN was infused intravenously for $0.5-1 \mathrm{~h}$ in adults and for $1 \mathrm{~h}$ in children, and this infusion was tolerated by all patients without serious adverse reaction.

Determination of GRN Blood samples were taken by venipuncture at $1.25,1.75,2,3,5,8,24,30,48 \mathrm{~h}$ after GRN infusion was started. They were centrifuged at $1500 \times \boldsymbol{g}$ for $10 \mathrm{~min}$ and the serum samples were taken and kept frozen at $-70^{\circ} \mathrm{C}$ until the quantitative assay. The subjects of this study are shown as $\mathbf{S}$ in Table 1. Urine was collected at $0-3,3-8$, $8-24,24-48,48-72,72-96 \mathrm{~h}$ after GRN infusion was begun. After urine volume was measured at each collection interval, an aliquot of the urine sample was kept frozen at 
Table 1. Patient Details and Diagnosis

\begin{tabular}{|c|c|c|c|c|c|c|c|c|}
\hline $\begin{array}{c}\text { Patient } \\
\text { No. }\end{array}$ & $\begin{array}{c}\text { Sex } \\
(\mathrm{M} / \mathrm{F})\end{array}$ & $\begin{array}{l}\text { Age } \\
\text { (year) }\end{array}$ & $\begin{array}{l}\text { Height } \\
(\mathrm{cm})\end{array}$ & $\begin{array}{l}\text { Weight } \\
(\mathrm{kg})\end{array}$ & Diagnosis & $\begin{array}{c}\text { TMN } \\
\text { classification }\end{array}$ & Stage & Sample \\
\hline \multicolumn{9}{|c|}{ Adults $(n=7)$} \\
\hline 1 & $\mathrm{~F}$ & 68 & 147.0 & 53.5 & $\mathrm{LC}$ & T4N2M1 & IV & $\mathrm{S}$ \\
\hline 2 & M & 65 & 171.0 & 72.0 & $\mathrm{LC}$ & T4N2M1 & IV & $\mathrm{S}$ \\
\hline 3 & M & 65 & 165.0 & 70.0 & $\mathrm{LC}$ & T4N2M1 & IV & $\mathrm{S}$ \\
\hline 4 & $\mathrm{M}$ & 69 & 155.0 & 56.0 & $\mathrm{LC}$ & T4N2M1 & IV & $\mathrm{S}+\mathrm{U}$ \\
\hline 5 & M & 66 & 167.3 & 59.8 & $\mathrm{LC}$ & T4N3M0 & $\mathrm{III}_{\mathrm{B}}$ & $\mathrm{S}+\mathrm{U}$ \\
\hline 6 & $\mathrm{~F}$ & 71 & 151.0 & 61.0 & $\mathrm{LC}$ & T4N2M1 & IV & U \\
\hline 7 & M & 67 & 168.5 & 46.6 & $\mathrm{LC}$ & $\mathrm{T} 2 \mathrm{~N} 3 \mathrm{M} 1$ & IV & $\mathrm{U}$ \\
\hline \multicolumn{9}{|c|}{ Children $(n=7)$} \\
\hline 8 & M & 2 & 89.0 & 15.9 & ALL & & & $\mathrm{S}$ \\
\hline 9 & $\mathrm{~F}$ & 8 & 129.6 & 27.1 & ALL & & & $\mathrm{S}$ \\
\hline 10 & $\mathrm{~F}$ & 11 & 137.0 & 30.2 & ALL & & & $\mathrm{S}$ \\
\hline 11 & M & 15 & 177.0 & 59.0 & ALL & & & $\mathrm{S}+\mathrm{U}$ \\
\hline 12 & M & 12 & 144.5 & 46.0 & ALL & & & $\mathrm{S}+\mathrm{U}$ \\
\hline 13 & $\mathrm{M}$ & 14 & 158.0 & 35.0 & $\mathrm{MT}$ & & & $\mathrm{S}+\mathrm{U}$ \\
\hline 14 & $\mathrm{M}$ & 14 & 170.5 & 61.8 & ALL & & & $\mathrm{S}+\mathrm{U}$ \\
\hline
\end{tabular}

LC, lung cancer; ALL, acute lymphocytic leukemia; MT, mediastinal tumor; S, serum; U, urine.

$-20^{\circ} \mathrm{C}$ until assay. The subjects from whom urine samples were collected are shown as $\mathbf{U}$ in Table 1.

The determination of GRN in serum and urine sample was done as follows: $0.5 \mathrm{ml}$ of serum or urine sample was mixed with $0.1 \mathrm{ml}$ of the internal standard (BRL 43693A) aqueous solution and $0.4 \mathrm{ml}$ of ammonium acetate buffer ( $\mathrm{pH} 9)$. This mixture was then loaded onto an Extrelut ${ }^{\mathbb{B}}-1$ cartridge column (Merck, Darmstadt, Germany). After 15 min, GRN was eluted with 3 and $4 \mathrm{ml}$ of dichloromethane. The elute was evaporated to dryness under a nitrogen stream at $40^{\circ} \mathrm{C}$. The residue was reconstituted with $100 \mu \mathrm{l}$ of mobile phase and 20 $\mu \mathrm{l}$ was applied to HPLC. The HPLC system used was a Shimadzu LC-10A (Kyoto, Japan) equipped with a Shimadzu RF-10A fluorescence detector and Shimadzu CTO-10A column oven. Chromatographic condition were as follows: ${ }^{7)}$ column, LiChroCART ${ }^{\circledR}$ packed with LiChrospher $100 \mathrm{CN}$ (CicaMerck, $250 \times 4 \mathrm{~mm}$ i.d., $5 \mu \mathrm{m}$ ); mobile phase, $0.1 \mathrm{~m}$ acetate buffer (pH 3.5)-acetonitrile (7:3); flow rate, $1 \mathrm{ml} / \mathrm{min}$; column temperature, $40^{\circ} \mathrm{C}$; detector, $290 \mathrm{~nm}$ for excitation and $365 \mathrm{~nm}$ for emission.

Pharmacokinetic Analysis The pharmacokinetic parameters were calculated as a two-compartment model using the computer software, Phaconet-two ${ }^{\circledR}$ (ver. 2.1, System wave, Tokyo).

\section{RESULTS AND DISCUSSION}

In this study, GRN was administered only once to control the first episode of nausea. In all cases, vomiting was not observed at this first administration, and no adverse effect due to GRN was observed. Figure 1 shows the elimination profiles of GRN from serum after intravenous infusion to five adult patients with lung cancer. The serum concentrations of GRN decreased biphasically in each patient. The pharmacokinetic parameters obtained are shown in Table 3. Contrary to previous reports, the variations in $t_{1 / 2 \beta}, A U C$, and $\beta$-phase volume of distribution $\left(V d_{\beta}\right)$ seemed relatively small among these patients. It has been summarized that the range of mean values in $C_{\max }, t_{1 / 2 \beta}, A U C, V d$, and clearance $(C L)$ were $19.5-63.0 \mu \mathrm{g} / \mathrm{l}, \quad 3.1-4.0 \mathrm{~h}, \quad 63-189 \mu \mathrm{g} / 1 \cdot \mathrm{h}, \quad 174-1961$, and $33.4-51.41 / \mathrm{h}$ in healthy subjects, respectively. ${ }^{3)}$ The

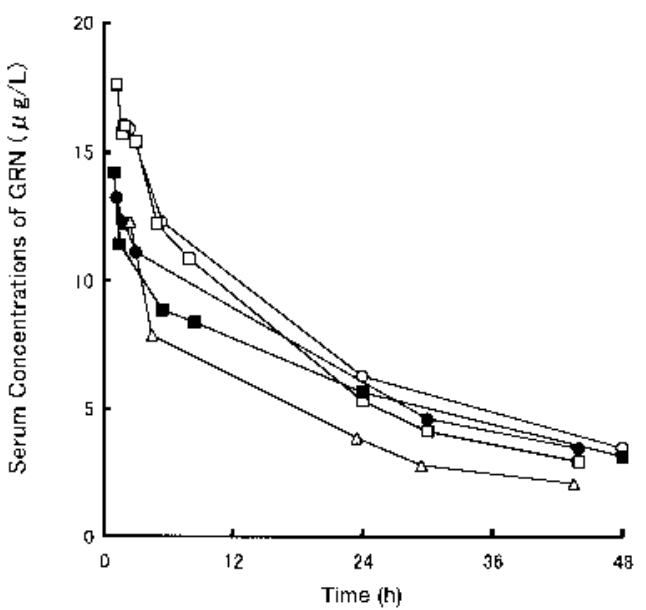

Fig. 1. Time Courses of GRN Concentration in Serum after Intravenous Infusion to Five Adult Patients with Lung Cancer

Patients were administered $3 \mathrm{mg}$ of GRN by infusion for $0.5-1 \mathrm{~h}$. Key: $\bigcirc$, patient 1 ; $\boldsymbol{0}$, patient $2 ; \square$, patient $3 ; \mathbf{\square}$, patient $4 ; \triangle$, patient 5 .

dose and infusion time in the present study was almost similar to those in the previous studies with healthy subjects. ${ }^{3)}$ It is, therefore, thought that $C_{\max }$ was in similar range and that $A U C, t_{1 / 2 \beta}$, and $V d_{\beta}$ were much greater in lung cancer patients than in healthy subjects. Especially, $t_{1 / 2 \beta}$ was prolonged more than 5 -fold. The range of mean values of $C_{\max }, t_{1 / 2 \beta}$, $A U C, V d$, and $C L$, which had been reported for various cancer patients previously, was $27.2-37.5 \mu \mathrm{g} / 1,9.0-11.6 \mathrm{~h}$, $238-350 \mu \mathrm{g} / \mathrm{l} \cdot \mathrm{h}, 154-228 \mathrm{l}$, and $14.9-26.3 \mathrm{l} / \mathrm{h}$, respectively. ${ }^{3)} C_{\max }$ of lung cancer patients in this study were in similar range to that reported previously, ${ }^{3)}$ however, $t_{1 / 2 \beta}$ was much longer than those in previous studies. The mean $A U C$ and $V d_{\beta}$ in this study was slightly greater. The bedridden elderly patients in this study were in the terminal stage of lung cancer, and it was, therefore, probable that they had extracellular fluids like thoracic effusion and edema as the third space for the distribution of GRN. In a recent paper, ${ }^{7)}$ we reported that intravenously administered GRN was rapidly and highly distributed throughout the pleural effusion and then disappeared from the pleural effusion in a two-compartment model. It might be assumed that an elimination route of 
GRN, which distributed into the third space, is back-diffusion into the blood-stream. If so, slow and continuous backdiffusion of GRN into blood retards its disappearance from blood and then prolongs $t_{1 / 2 \beta}$ in the patients with lung cancer. Recently, we have shown that $t_{1 / 2 \beta}$ of etoposide was significantly prolonged in lung cancer patients with pleural effusion. ${ }^{8)}$

Cumulative urinary excretion ratios of unchanged GRN in four adult patients (No. 4-7) are presented in Fig. 2. The amount of unchanged GRN excreted into urine for $96 \mathrm{~h}$ was

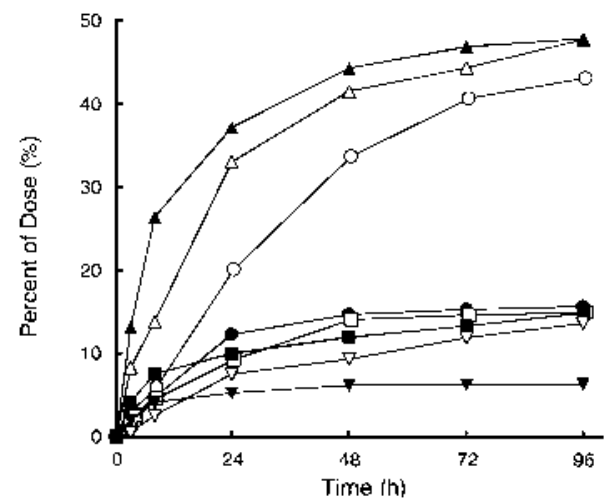

Fig. 2. Urinary Excretion Ratios of GRN after Intravenous Infusion to Eight Patients

Key: $\bigcirc$, patient $4 ; \boldsymbol{\bullet}$, patient $5 ; \square$, patient $6 ; \boldsymbol{\square}$, patient $7 ; \triangle$, patient $11 ; \boldsymbol{\Delta}$, patient $12 ; \nabla$, patient $13 ; \boldsymbol{\nabla}$, patient 14 . almost the same in three of the patients (except patient 4 ) and was approximately $15 \%$ of the dose. The value was consistent with those reported previously. ${ }^{9}$ ) The hepatic and renal function of patient 4 seem normal, as shown in Table 2. It seems unlikely that concomitantly administered etoposide enhanced urinary excretion of unchanged GRN in this patient, because it was commonly administered to patients 5 and 6 in this study. As shown in Table 3, the extra renal clearance $\left(C L_{\mathrm{E}}\right)$ was smaller in patient 4 than in patient 5 ( 0.071 vs. $0.133 \mathrm{l} / \mathrm{h} / \mathrm{kg}$ ). Since it is known that GRN is extensively metabolized by CYP3A4, the metabolism in the liver is considered an important factor of the $C L_{\mathrm{E}}$ of GRN after intravenous infusion. Therefore, it is likely that CYP3A4 was less active in patient 4 than in patient 5 . Because we did not determine the metabolites of GRN in this study, we were unable to identify the exact reason for much greater renal excretion of unchanged GRN observed in patient 4.

The elimination profiles of serum GRN and pharmacokinetic parameters after intravenous infusion to seven child patients (No. 8-14) are shown in Fig. 3 and Table 4, respectively. Distinct from adult cancer patients shown in Fig. 1, serum GRN concentration markedly varied among the children. $C_{\max }, t_{1 / 2 \beta}, A U C, V d_{\beta}$, and $C L_{\text {tot }}$ ranged 31.8-104.2 $\mu \mathrm{g} / \mathrm{l}, \quad 7.8-66.8 \mathrm{~h}, \quad 315.4-1006.1 \mu \mathrm{g} / \mathrm{l} \cdot \mathrm{h}, \quad 1.01-7.66 \mathrm{l} / \mathrm{kg}$, and $0.051-0.253 \mathrm{l} / \mathrm{h} / \mathrm{kg}$, respectively. GRN rapidly disappeared from the serum in patients 13 and 14 . The time courses of urinary excretion of unchanged GRN in four child patients (No. 11-14) are shown in Fig. 3. In patients 11 and

Table 2. Patient Characteristics

\begin{tabular}{|c|c|c|c|c|c|c|c|}
\hline $\begin{array}{l}\text { Patient } \\
\text { No. }\end{array}$ & $\begin{array}{l}\text { GRN dose } \\
(\mathrm{mg})\end{array}$ & $\begin{array}{l}\text { Infusion time } \\
\text { (h) }\end{array}$ & $\begin{array}{l}\text { Other drugs concomitantly } \\
\text { administered }\end{array}$ & $\begin{array}{l}\text { GOT } \\
(\mathrm{U} / 1)\end{array}$ & $\begin{array}{l}\text { GPT } \\
(\mathrm{U} / 1)\end{array}$ & $\begin{array}{c}\text { BUN } \\
(\mathrm{mg} / \mathrm{dl})\end{array}$ & $\begin{array}{c}\mathrm{SCr} \\
(\mathrm{mg} / \mathrm{dl})\end{array}$ \\
\hline 1 & 3.0 & 1.0 & $\mathrm{CDDP}+\mathrm{VP} 16$ & 15 & 15 & 10.5 & 0.61 \\
\hline 2 & 3.0 & 1.0 & CBDCA & 18 & 10 & 8.6 & 0.69 \\
\hline 3 & 3.0 & 1.0 & $\mathrm{CDDP}+\mathrm{VP} 16$ & 27 & 26 & 13.2 & 0.85 \\
\hline 4 & 3.0 & 0.5 & VP16 & 31 & 27 & 10.7 & 0.20 \\
\hline 5 & 3.0 & 0.5 & $\mathrm{CDDP}+\mathrm{VP} 16$ & 18 & 23 & 12.3 & 0.79 \\
\hline 6 & 3.0 & 0.5 & $\mathrm{CBDCA}+\mathrm{VP} 16$ & 15 & 13 & - & 0.46 \\
\hline 7 & 3.0 & 1.0 & CDDP & 36 & 36 & 13.3 & 0.69 \\
\hline 8 & 1.0 & 1.0 & $\mathrm{CPA}+\mathrm{Ara}-\mathrm{C}+6-\mathrm{MP}+\mathrm{L}-\mathrm{Asp}$ & 33 & 27 & 10.5 & 0.26 \\
\hline 9 & 2.0 & 1.0 & $\mathrm{MTX}+\mathrm{L}-\mathrm{Asp}$ & 26 & 14 & 8.8 & 0.40 \\
\hline 10 & 2.0 & 1.0 & $\mathrm{VCR}+\mathrm{MIT}$ & 17 & 11 & 16.4 & 0.32 \\
\hline 11 & 3.0 & 1.0 & 6-MPR & 14 & 45 & 12.1 & 0.93 \\
\hline 12 & 3.0 & 1.0 & $\mathrm{VCR}+\mathrm{MIT}+\mathrm{PRN}$ & 65 & 71 & 10.6 & 0.42 \\
\hline 13 & 3.0 & 1.0 & $\mathrm{CDDP}+\mathrm{VP} 16+\mathrm{BLM}$ & 16 & 13 & 7.9 & 0.47 \\
\hline 14 & 3.0 & 1.0 & MTX & 19 & 41 & 9.1 & 0.70 \\
\hline
\end{tabular}

CDDP, cisplatin; VP16, etoposide; CBDCA, carboplatin; 6-MPR, 6-mercaptopurine reboside; VCR, vincristine; MIT, mitoxantrone; PRN, prednisolone; CPA, cyclophosphamide; Ara-C, cytarabine; 6-MP, 6-mercaptopurine; L-Asp, L-asparaginase; MTX, methotrexate; BLM, bleomycin; BUN, blood urea nitrogen; SCr, serum creatinine.

Table 3. Pharmacokinetic Parameters of GRN in Adults $(n=5)$

\begin{tabular}{|c|c|c|c|c|c|c|c|c|c|c|c|c|c|c|}
\hline $\begin{array}{c}\text { Patient } \\
\text { No. }\end{array}$ & $\begin{array}{c}\text { Dose } \\
(\mu \mathrm{g} / \mathrm{kg})\end{array}$ & $\begin{array}{c}k_{\mathrm{e}} \\
\left(\mathrm{h}^{-1}\right)\end{array}$ & $\begin{array}{c}k_{12} \\
\left(\mathrm{~h}^{-1}\right)\end{array}$ & $\begin{array}{c}k_{21} \\
\left(\mathrm{~h}^{-1}\right)\end{array}$ & $\begin{array}{c}\alpha \\
\left(\mathrm{h}^{-1}\right)\end{array}$ & $\begin{array}{c}\beta \\
\left(\mathrm{h}^{-1}\right)\end{array}$ & $\begin{array}{c}C_{\max } \\
(\mu \mathrm{g} / 1)\end{array}$ & $\begin{array}{l}t_{1 / 2 \beta} \\
(\mathrm{h})\end{array}$ & $\begin{array}{c}A U C \\
(\mu \mathrm{g} / \mathrm{l} \cdot \mathrm{h})\end{array}$ & $\begin{array}{c}V d_{\beta} \\
(1 / \mathrm{kg})\end{array}$ & $\begin{array}{c}V d_{\mathrm{ss}} \\
(1 / \mathrm{kg})\end{array}$ & $\begin{array}{c}C L_{\text {tot }} \\
(1 / \mathrm{h} / \mathrm{kg})\end{array}$ & $\begin{array}{c}C L_{\mathrm{R}} \\
(1 / \mathrm{h} / \mathrm{kg})\end{array}$ & $\begin{array}{c}C L_{\mathrm{E}} \\
(1 / \mathrm{h} / \mathrm{kg})\end{array}$ \\
\hline 1 & 56.1 & 0.053 & 0.149 & 0.226 & 0.397 & 0.030 & 22.2 & 23.0 & 439 & 4.24 & 3.99 & 0.128 & - & - \\
\hline 2 & 41.7 & 0.037 & 0.151 & 0.408 & 0.570 & 0.027 & 13.8 & 26.0 & 404 & 3.88 & 3.81 & 0.103 & - & - \\
\hline 3 & 42.9 & 0.047 & 0.045 & 0.116 & 0.177 & 0.031 & 17.5 & 22.5 & 390 & 3.57 & 3.24 & 0.110 & - & - \\
\hline 4 & 53.6 & 0.079 & 1.633 & 0.739 & 2.427 & 0.024 & 23.8 & 28.8 & 428 & 5.19 & 5.07 & 0.125 & 0.054 & 0.071 \\
\hline 5 & 50.2 & 0.152 & 0.690 & 0.201 & 1.013 & 0.030 & 39.8 & 22.9 & 318 & 5.22 & 4.59 & 0.158 & 0.025 & 0.133 \\
\hline Mean & 48.9 & 0.074 & 0.534 & 0.338 & 0.917 & 0.028 & 23.4 & 24.7 & 396 & 4.42 & 4.14 & 0.125 & & \\
\hline S.D. & 6.4 & 0.047 & 0.665 & 0.248 & 0.898 & 0.003 & 10.0 & 2.7 & 47.6 & 0.76 & 0.71 & 0.021 & & \\
\hline $\operatorname{cv}(\%)$ & 13.1 & 63.2 & 124.5 & 73.4 & 98.0 & 10.2 & 42.5 & 10.9 & 12.0 & 17.1 & 17.1 & 16.9 & & \\
\hline
\end{tabular}

$V d_{\mathrm{ss}}$, steady-state volume of distribution; $C L_{\text {tot }}$, total clearance; $C L_{\mathrm{R}}$, renal clearance; $C L_{\mathrm{E}}$, extra renal clearance. 
Table 4. Pharmacokinetic Parameters of GRN in Children $(n=7)$

\begin{tabular}{|c|c|c|c|c|c|c|c|c|c|c|c|c|c|c|}
\hline $\begin{array}{c}\text { Patient } \\
\text { No. }\end{array}$ & $\begin{array}{c}\text { Dose } \\
(\mu \mathrm{g} / \mathrm{kg})\end{array}$ & $\begin{array}{c}k_{\mathrm{e}} \\
\left(\mathrm{h}^{-1}\right)\end{array}$ & $\begin{array}{c}k_{12} \\
\left(\mathrm{~h}^{-1}\right)\end{array}$ & $\begin{array}{c}k_{21} \\
\left(\mathrm{~h}^{-1}\right)\end{array}$ & $\begin{array}{c}\alpha \\
\left(\mathrm{h}^{-1}\right)\end{array}$ & $\begin{array}{c}\beta \\
\left(\mathrm{h}^{-1}\right)\end{array}$ & $\begin{array}{c}C_{\max } \\
(\mu \mathrm{g} / 1)\end{array}$ & $\begin{array}{l}t_{1 / 2 \beta} \\
\text { (h) }\end{array}$ & $\begin{array}{c}A U C \\
(\mu \mathrm{g} / \mathrm{l} \cdot \mathrm{h})\end{array}$ & $\begin{array}{c}V d_{\beta} \\
(1 / \mathrm{kg})\end{array}$ & $\begin{array}{c}V d_{\mathrm{ss}} \\
(1 / \mathrm{kg})\end{array}$ & $\begin{array}{c}C L_{\text {tot }} \\
(1 / \mathrm{h} / \mathrm{kg})\end{array}$ & $\begin{array}{c}C L_{\mathrm{R}} \\
(1 / \mathrm{h} / \mathrm{kg})\end{array}$ & $\begin{array}{c}C L_{\mathrm{E}} \\
(1 / \mathrm{h} / \mathrm{kg})\end{array}$ \\
\hline 8 & 62.9 & 0.145 & 0.348 & 0.155 & 0.611 & 0.037 & 36.4 & 18.9 & 315.4 & 5.44 & 4.47 & 0.199 & - & - \\
\hline 9 & 73.8 & 0.628 & 6.807 & 0.936 & 8.299 & 0.071 & 104.2 & 9.8 & 792.7 & 1.32 & 1.23 & 0.093 & - & - \\
\hline 10 & 66.3 & 0.091 & 0.250 & 0.816 & 1.089 & 0.068 & 76.3 & 10.2 & 966.0 & 1.01 & 0.99 & 0.069 & - & - \\
\hline 11 & 50.8 & 0.033 & 0.025 & 0.022 & 0.070 & 0.010 & 31.8 & 66.8 & 1006.1 & 4.87 & 3.32 & 0.051 & 0.024 & 0.026 \\
\hline 12 & 65.2 & 0.114 & 0.651 & 0.702 & 1.411 & 0.057 & 78.0 & 12.2 & 916.5 & 1.25 & 1.20 & 0.071 & 0.034 & 0.037 \\
\hline 13 & 85.7 & 0.173 & 0.270 & 0.097 & 0.507 & 0.033 & 47.5 & 21.0 & 339.1 & 7.66 & 5.55 & 0.253 & 0.035 & 0.218 \\
\hline 14 & 48.6 & 0.156 & 1.131 & 1.606 & 2.803 & 0.089 & 46.4 & 7.8 & 435.7 & 1.22 & 1.22 & 0.112 & 0.007 & 0.104 \\
\hline Mean & 64.8 & 0.191 & 1.355 & 0.619 & 2.113 & 0.052 & 60.1 & 20.9 & 681.6 & 3.25 & 2.57 & 0.121 & 0.025 & 0.097 \\
\hline S.D. & 12.8 & 0.198 & 2.431 & 0.572 & 2.867 & 0.027 & 26.6 & 20.8 & 307.0 & 2.70 & 1.87 & 0.076 & 0.013 & 0.088 \\
\hline $\operatorname{cv}(\%)$ & 19.8 & 103.6 & 179.4 & 92.4 & 135.7 & 51.7 & 44.2 & 99.4 & 45.0 & 83.1 & 73.0 & 62.7 & 51.5 & 91.3 \\
\hline
\end{tabular}

$V d_{\text {ss }}$, steady-state volume of distribution; $C L_{\text {tot }}$, total clearance; $C L_{\mathrm{R}}$, renal clearance; $C L_{\mathrm{E}}$, extra renal clearance.

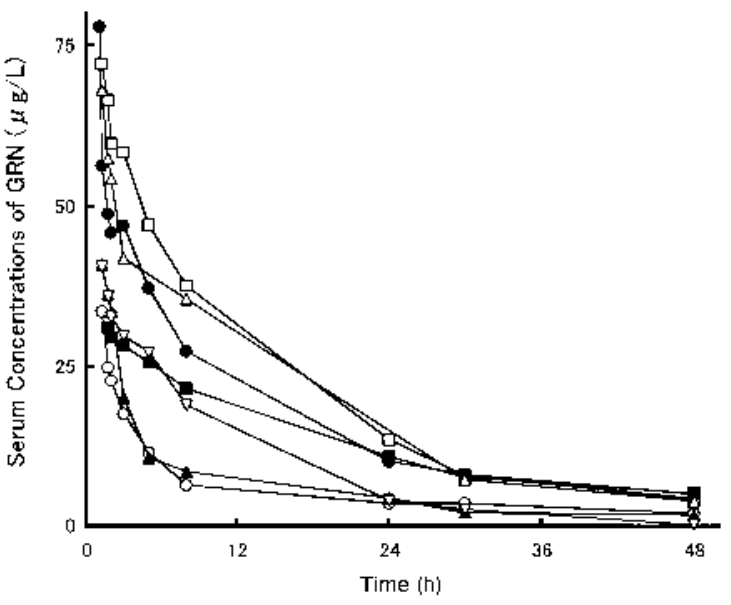

Fig. 3. Time Courses of GRN Concentration in Serum after Intravenous Infusion to Seven Child Cancer Patients

Patients were administered $1-3 \mathrm{mg}$ of GRN by infusion for $1 \mathrm{~h}$. Key: $\bigcirc$, patient 8 $\boldsymbol{\bullet}$, patient $9 ; \square$, patient $10 ; \mathbf{\square}$, patient $11 ; \triangle$, patient $12 ; \boldsymbol{\Delta}$, patient $13 ; \nabla$, patient 14 .

12, the cumulative amount excreted increased with time up to $96 \mathrm{~h}$ and reached $c a .45 \%$ of the dose. On the other hand, the percent of unchanged GRN excreted for $96 \mathrm{~h}$ was much smaller in patients 13 and 14 in spite of rapid disappearance from the serum. The $C L_{\mathrm{E}}$ was calculated to be more than 3 times greater in patients 13 and 14 than in patients 11 and 12 (Table 4); therefore, GRN might have been rapidly metabolized in patients 13 and 14 . The renal clearance was very low in patient $14(0.007 \mathrm{l} / \mathrm{h} / \mathrm{kg})$, and it might be necessary to consider the influence of methotrexate. It should be noted that various other factors such as the disease process, alteration in plasma protein binding and the changes in extracellular fluids are closely involved in significant inter-subject differences in pharmacokinetic parameters among child cancer patients, either alone or combination. Various antineoplastic agents were administered concomitantly with GRN to child cancer patients in the present study (Table 2), making, it impossible to exclude that drug interaction between GRN and these agents influenced serum concentration profiles and urinary excretion ratios of unchanged GRN. However, little information is available in the literature on the drug interaction of GRN.

The relationship between blood levels and anti-emetic ef- fects of GRN has not yet been fully evaluated. Therefore, when the effect of GRN is not adequate following its first administration, a subsequent administration is often performed in a short interval without considering the clinical pharmacokinetics of the drug. This is the reason many studies have rated the adverse effects of GRN as mild to moderate and concluded that GRN is a relatively safe $5-\mathrm{HT}_{3}$ receptor antagonist. ${ }^{9,10)}$ The frequency of adverse effects in the healthy subjects is certainly minimal. Several adverse effects of GRN such as headache, sedation, elevation in hepatic transaminase activity and constipation have been reported. ${ }^{10)}$ However, most studies on such adverse effects were performed in adult cancer patients and clinical evidence insufficient to support that GRN is a safe drug in child patients. Because it is used together with antineoplastic agents in most case, its adverse effect might be covered by stronger adverse effects of these agents. According to the present results, it seems impossible to predict GRN blood levels in child cancer patients even after intravenous infusion. Therefore, a possibility still remains that unknown and more severe adverse effects might occur in this group when $C_{\max }$ and $A U C$ are unexpectedly increased. Further pharmacokinetic studies on GRN seem necessary to extend our understanding on GRN dosage regimen and its clinical effects.

Acknowledgment We are grateful to Smith Kline Beecham Pharm. Co. for the supply of GRN and BRL43693A.

\section{REFERENCES AND NOTES}

1) Gregory R. E., Ettinger D. S., Drugs, 55, 173-189 (1998).

2) Wilder-Smith O. H., Borgeat A., Chappauis P., Fathi M., Forni M., Cancer, 72, 2239-2241 (1993).

3) Yarker Y. E., McTavish D., Drugs, 48, 761 - 793 (1994).

4) Bloomer J. C., Baldwin S. J., Smith G. J., Ayrton A. D., Clark R. J., Chenery R. J., Br. J. Clin. Pharmacol., 38, 557-566 (1994).

5) Guengerich F. P., Annu. Rev. Pharmacol. Toxicol., 39, 1-17 (1999).

6) Craft A. W., Price L., Eden O. B., Shaw P., Campbell R., Pierce D. M., Murdoch R., Upward J., Med. Pediatr. Oncol., 25, 28-32 (1995).

7) Wada I., Satoh M., Takeda T., Nakabayashi T., Honma T., Saitoh H., Takada M., Hirano K., Biol. Pharm. Bull., 21, 535-537 (1998).

8) Wada I., Yokouchi M., Saitoh H., Takada M., Nakabayashi T., Mino K., Honma T., Takeda T., Hirano K., Int. J. Clin. Pharmacol. Ther., 37, 254-259 (1999).

9) Tsukagoshi S., Gan To Kagaku Ryoho, 26, 1001-1008 (1999).

10) Diehl V., Marty M., Cancer Treat. Rev., 20, 379-392 (1994). 